\title{
Олена Плєшакова
}

\author{
Київський національний університет культури та мистецтв, Київ, Україна
}

Анотація. Діяльність сучасних освітніх закладів спрямована на забезпечення підтримання й збереження здоров'я учнівської молоді, а процес підготовки висококваліфікованих фахівців супроводжується заходами здоров'язбережувального характеру. Відомо, що одним із ключових фракторів збереження здоров'я людини є оптимальний руховий режим. На жаль, у студентської молоді часто спостерігається недостатній рівень фрізичної активності. У статті порушуються питання, пов'язані зі зниженням фізичної активності студентів закладів вищої освіти в особливий період запровадження карантинних заходів. Наше припущення полягало в тому, що перехід закладів вищої освіти до дистанційної форми навчання супроводжується зниженням рівня фізичної активності студентської молоді. Проте наукових даних, які підтверджували б цю гіпотезу в доступних наукових джерелах не виявлено. Мета. Діагностика рівня фрізичної активності студенток гуманітарного закладу вищої освіти у період запровадження дистанційної форми навчання. Методи. Аналіз науково-методичної літератури, власних досліджень, опитування. Результати. У дослідженні представлено результати опитування 52 студенток Київського національного університету культури та мистецтв. Оцінювання фізично активності студенток здійснювали за допомогою міжнародного опитувальника International Ques-tionnaire on Physical Activity. Встановлено, що у період дистанційного навчання, обумовленого карантинними заходами, студентки характеризуються помірним рівнем фізичної активності. Проте дедалі більше вони схиляються до малорухливого способу життя. Найменшу енергетичну вартість забезпечували помірні фрізичні навантаження, а найбільшу щотижневу метаболічну активність в них діагностовано при ходьбі. Порівнюючи отримані дані з результатами, представленими в літературних джерелах, констатовано різке зниження їхньої щотижневої метаболічної активності. Спостерігалось зростання частки студенток, які проводять тривалий час сидячи та таких, які менше 10 хв мали інтенсивні фрізичні навантаження за рахунок скорочення відсотка тих, котрі більше часу приділяли інтенсивним фрізичним навантаженням. Отримані результати підтверджують висунуту гіпотезу про критичне зниження фізичної активності студенток в умовах дистанційного навчання.

Ключові слова: студентки, дистанційне навчання, фрізична активність, фрізичні навантаження, метаболічна активність.

\section{Olena Pleshakova}

\section{FEATURES OF PHYSICAL ACTIVITY OF HIGHER EDUCATION INSTITUTION STUDENTS IN THE CONDITIONS OF DISTANCE LEARNING}

Abstract. The activities of modern educational institutions are aimed at ensuring and maintaining the health of young students, and the process of training highly qualified professionals is accompanied by measures of health protecting character. It is known that one of the key factors in maintaining human health is optimal motor mode. Unfortunately, an insufficient level of physical activity is frequently observed in students. The article raises issues related to the reduction of physical activity of higher education institution students during the special period of quarantine measures. Our assumption was that the transition of higher education institutions to distance learning is accompanied by a decrease in the level of physical activity of student youth. However, scientific data that would confirm this hypothesis in the available scientific sources were not found. Objective. Diagnosis of physical activity level in female students of the humanitarian institution of higher education during the introduction of distance learning. Methods. Analysis of scientific and methodological literature, own research, surveys. Results. The study presents the results of a survey of 52 students of Kyiv National University of Culture and Arts. The International Questionnaire on Physical Activity was used to assess the physical activity level of female students. It has been established that in the period of distance learning due to quarantine measures, female students are characterized by a moderate level of physical activity. However, they are increasingly inclined to a sedentary lifestyle. The lowest energy value was provided

Pleshakova 0. Features of physical activity of higher education institution students in the conditions of distance learning. Theory and Methods of Physical education and sports. 2020; 4: 86-89

DOI: 10.32652/tmfvs.2020.4.86-89
Плєшакова 0. Особливості фізичної активності студентів закладів вищої освіти в умовах дистанційного навчання Теорія і методика фрізичного виховання і спорту. 2020; 4: 86-89

DOI: 10.32652/tmfvs.2020.4.86-89
Вступ. Діяльність сучасних освітніх закладів спрямована на забезпечення підтримання й збереження здоров'я учнівської молоді, а процес підготовки висококваліфікованих фахівців супроводжується заходами здоров'язбережувального характеру 3 метою подолання негативної тенденції, пов'язаної зі зниженням рівня фізичного здоров'я населення протягом останніх п'яти років, спричинене зміною стилю життя молоді в умовах розвиненого інфрормаційного суспільства $[2,3]$. Незважаючи на те що одним із ключових факторів збереження здоров'я людини є оптимальний руховий режим, дослідники констатують, що в структурі дозвілля молоді часто відсутні фрізичні навантаження достатнього обсягу й інтенсивності. Відтак вчені зорієнтовані на пошук шляхів для залучення студентів до активного способу життя, їх дослідження спрямовані на оцінювання впливу рухової активності на стан здоров'я студентів, вивчення проявів та функцій рухової активності, які мають вирішальний вплив на їхнє фрізичне здоров'я $[1,3,10]$.

у процесі оцінювання фрізичної активності студентської молоді науковці сходяться на думці про її недостатній обсяг. Так, М. Редькіна [9] стверджує про переважання сидячого й малого рівнів у структурі добової рухової активності студентів. У свою чергу А. Цьось [11] встановив, що $54 \%$ сучасних студентів нераціонально використовують позанавчальний час та в цілому недостатньо умотивовані на заняття різними видами рухової активності, а А. Ковтун [4] свідчить про недостатні величини енерговитрат студенток на середньому та високому рівнях рухової активності за рахунок проведення ними більшості часу в статичному положенні. Досліджуючи рухову активність студенток з ожирінням, І. Миронюк, М. Дуб [5] зазначають, що вони характеризуються малорухомим способом життя, та приходять до висно- 
by moderate physical activity, and the highest weekly metabolic activity was diagnosed when walking. Comparing the obtained data with the results presented in the literature, a sharp decrease in their weekly metabolic activity was noted. There was an increase in the share of female students who spend a long time sitting and those who had less than 10 minutes of intense physical activity at the expense of a reduction in the percentage of those who spent more time on intense physical activity. The findings confirm the hypothesis of a critical decrease in physical activity of female students in the conditions of distance learning.

Keywords: female students, distance teaching, physical activity, physical loads, metabolic activity.

вку, що відсутність або недостатність інтенсивних і неінтенсивних фрізичних навантажень є патогенетичним фрактором розвитку ожиріння.

Попри окремі дослідження, в яких зафріксовано позитивну тенденцію ставлення сучасних студенток до рухової активності 3 початком навчання у закладах вищої освіти (3В0), науково обґрунтований тижневий обсяг їхніх навантажень [8], все таки ми схиляємося до думки, що в умовах дистанційної форми навчання рухова активність студентської молоді різко знизилася. Отже, питання моніторингу рухової активності студентської молоді стають дедалі більш актуальними. Слід зазначити, що на сьогодні, окрім припущення про зниження рівня рухової активності студенток, немає достовірної інсрормації, що могла б спростувати або підтвердити цю гіпотезу.

Мета дослідження - оцінити рівень фрізичної активності студенток гуманітарного ЗВО під час запровадження дистанційної форми навчання.

Методи дослідження: оцінку фізичної активності студенток здійснювали за допомогою міжнародного опитувальника International Ques-tionnaire on Physical Activity, заснованого на врахуванні фрізичної активності за тиждень й призначеного для масових обстежень осіб від 15 до 69 років.

Результати дослідження та їх обговорення. У ході дослідження, в якому взяли участь 52 студентки I-ІІ курсу Київського національного університету культури та мистецтв, оцінювали метаболічний еквівалент завдання (MET, хв - тиж. $\left.{ }^{-1}\right)$, який являє собою фрізіологічний показник для вираження енергетичної вартості фрізичних навантажень і показує щотижневу метаболічну активність під час ходьби, а також помірних і енергійних фрізичних навантаженнях.

Обробку емпіричних даних здійснювали за допомогою статистичного аналізу $[13,14,16]$, під час якого ви- значали середньостатистичні показники у вигляді (x; s), де $x$ - середнє $s$ - стандартне відхилення. За допомогою критерію Шапіро-Уілка перевіряли відповідність експериментальних даних нормальному закону розподілу, й у випадку недоведеного їх підпорядкування нормальному закону розподілу середні величини було представлено через медіану й 25 та 75 процентилі (Me; 25; 75). Гіпотезу про рівномірність форми розподілу студенток за рівнями рухової активності перевіряли за допомогою критерію $\chi^{2}$ на рівні статистичної значущості $\alpha=0,05$ $(p<0,05)$.

Особливий період, пов'язаний 3 карантинними заходами, серед яких перехід освітніх закладів, зокрема 3В0, привів до дистанційної форми навчання. Поряд зі складнощами, що виникли у керівництва, адміністрації, навчально-педагогічних працівників та безпосередньо в студентів під час організації освітнього процесу, загострилася проблема зниження рухової активності всіх суб'єктів освіти Дійсно, організація освітнього процесу передбачає, що його учасники протягом робочого тижня тривалий час використовують інформаційнокомунікаційні технології (IKT) [1, 12, 15]. Окрім навчальних занять, проведених сидячи за комп'ютером, вони змушені й надалі працювати з IKT. Так, науково-педагогічні працівники за допомогою IKT отримують виконані студентами завдання, перевіряють їх, витрачають час на листування, вказуючи на помилки, здійснюють заповнення електронного журналу, після чого готують нові завдання у формі, яка прийнятна для оприлюднення у вигляді електронних навчально-методичних матеріалів та доступна для сприйняття в умовах екстериторіальної взаємодії учасників освітнього процесу та розміщує готові електронні матеріали на визначених адміністрацією інформаційних ресурсах. Зі сво- го боку, після закінчення занять, що проходять за розкладом ЗВ0, студенти також продовжують залишатися за комп'ютером, оскільки мають виконати завдання, організувати його доставку на перевірку викладачу, за необхідності виконати редагування й повторно надіслати на перевірку. Вочевидь, в умовах карантинних обмежень тривалість перебування учасників освітнього процесу для здійснення освітньої діяльності різко зросла. Враховуючи захоплення молод комп'ютерними іграми та спілкуванням у соціальних мережах під час дозвілля, можна прогнозувати, що період навчання в 2020 р. супроводжується тотальним зниженням рівня рухової активності населення, в тому числі студентської молоді.

У ході перевірки припущення про зниження рівня рухової активност студенток під час запровадження дистанційної форми навчання встановлено, що середня оцінка їхньої рухової активності становить 23,92; 5,57 бала, що відповідає нормі, яка, згідно з трактуванням розробників для категорії осіб від 18 до 39 років, має становити понад 21 бал. Проте розподіл студенток за рівнями рухової активності показав, що в 17,3 \% ( $n=9)$ характеризуються низьким рівнем рухової активності і в них спостерігаються ознаки гіподинамії (рис. 1).

Зазначимо, що статистична обробка даних дозволила встановити відмінність форми розподілу студенток від рівномірної, тобто серед учасниць дослідження статистично значуще $(p<0,05)$ переважала частка 3 помірним рівнем рухової активності.

Щотижнева метаболічна участь під час ходьби й виконання помірної та високої фрізичної активності студенток, що брали участь у дослідженні, становила від 495 до 5255 хв · тиж.- ${ }^{-1}$ Найменшу енергетичну вартість забезпечували помірні фрізичні навантаження, а найбільшу щотижневу метаболічну активність у них діагностовано під час ходьби (рис. 2).

Незважаючи на те що розробниками електронної версії опитувальника в рекомендаціях наголошено на необхідності присвячувати не менше 150 хв на тиждень фізичним навантаженням помірної інтенсивності для підтримання оптимального рівня фрі- 


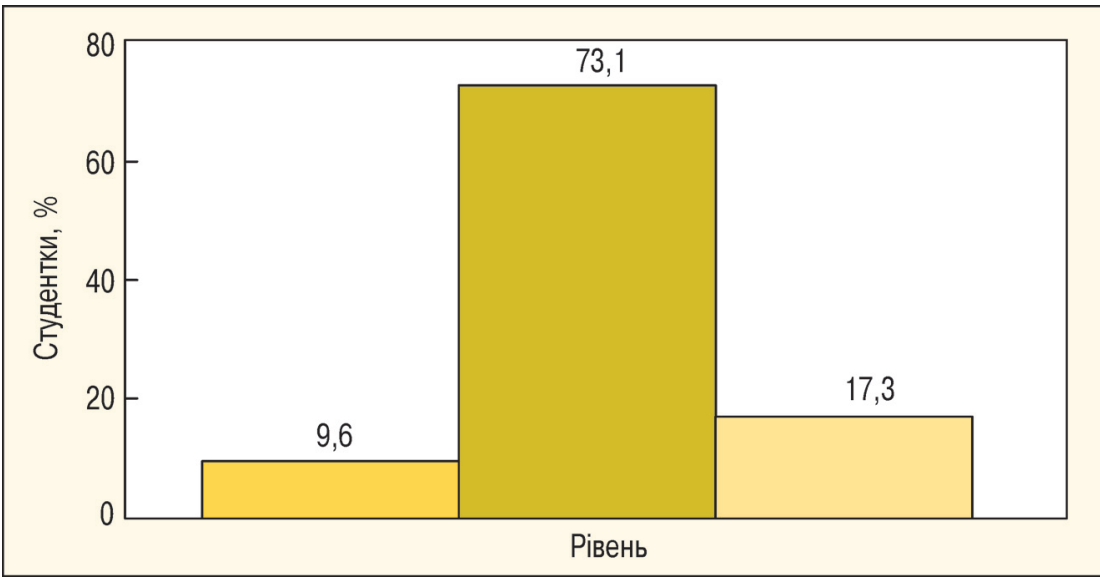

Рисунок 1 - Розподіл студенток I-ІІ курсів гуманітарних закладів вищої освіти за рівнем рухової активності ( $\mathrm{n}=52)$ : $\square$ - високий; $\square$ - середній; $\square$ - низький.

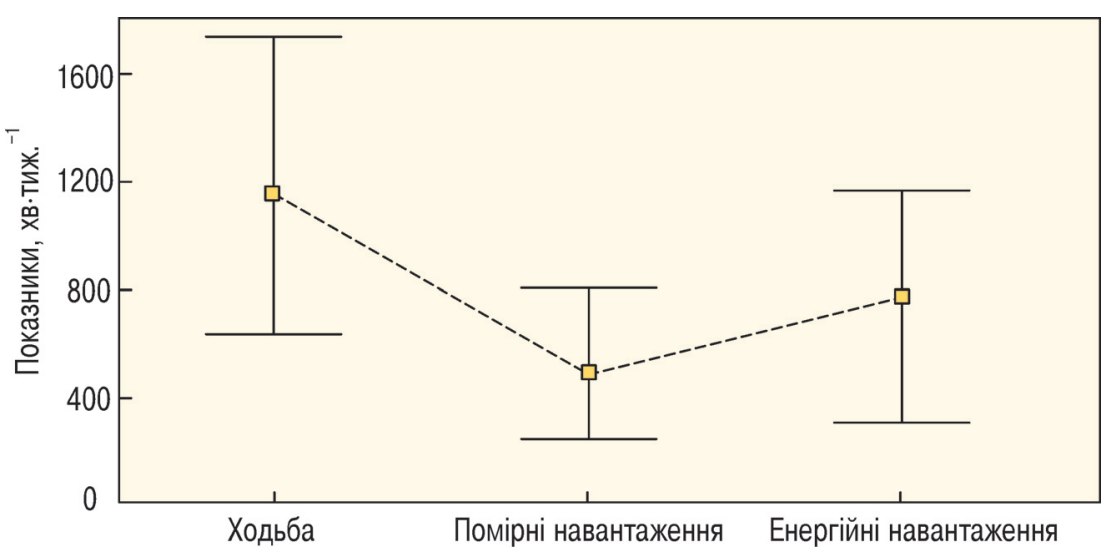

Рисунок 2 - Оцінка рухової активності студенток I-ІІ курсів гуманітарних закладів вищої освіти $(\mathrm{n}=52)$ :

-ㅁ-- медіана; $\square-25-75 \%$

зичного здоров'я, $11,5 \%(n=6)$ опитаних їх не мали. При цьому в студенток час, проведений сидячи, не відповідав гігієнічній нормі.

На наше переконання, існує нагальна потреба залучати студенток гуманітарних ЗВО до підвищення фізичної активності, враховуючи їхні рухові уподобання. Варто зосередитися на питаннях управління фізичним потенціалом студенток нефізкультурних ЗВО в умовах дистанційного навчання, в тому числі за рахунок відеоматеріалів, що містять комплекси фрізичних вправ із використанням засобів черлідингу [6, 7].

Дискусія. Порівнюючи отримані дані 3 даними науково-методичної і спеціальної літератури, наші результати виявилися зниженими. На противагу даним, отриманим Д. В. Попович [8], згідно 3 якими студентки продемонстрували високий рівень загальної рухової ак- чна частина студенток протягом тижня тривалий час перебуває в статичній позі сидячи: $21,2 \%(n=11)-$ від 4 до 5; $25 \%(n=13)$ - від 5 до 6; 26,9\% $(\mathrm{n}=14)$ - від 6 до 7 год. Вивчаючи частки респонденток, які займаються інтенсивними фрізичними вправами, бачимо, що їх розподіл мав такий вигляд: понад 1 год - 17,3 \% ( $n=9)$ респондентів, від 40 до 60 хв - 28,8 \% $(n=15), 20-40 \times B-30,8 \%(n=16)$, $10-20$ хв $-15,4 \%(n=8)$, а до 10 хв $7,7 \%(n=4)$. Порівнюючи з даними літературних джерел [2], можна помітити зростання частки студенток, які займалися менше 10 хв за рахунок скорочення відсотка тих, котрі займаються більш тривалий час. Вочевидь, у період дистанційного навчання, обумовленого карантинними заходами, вони схиляються до малорухливого способу життя.

Отримані результати дослідження, на жаль, підтверджують висунуту гіпотезу про критичне зниження рухової активності студенток в умовах дистанційного навчання.

Висновки. Незважаючи на необхідність дотримуватися оптимального рухового режиму для збереження й зміцнення здоров'я, сучасна студентська молодь у цілому має знижений рівень рухової активності й характеризується малорухомим способом життя, що обумовлено значним поширенням інсрормаційно-комунікаційних технологій. Перехід до дистанційної форми навчання у рамках запровадження карантинних заходів ще більше загострили наявну проблему.

у ході дослідження встановлено, що переважна більшість студенток гуманітарного ЗВО характеризується помірним рівнем рухової активності, проте у 17,3 \% з них виявлено ознаки гіподинамії. Порівнюючи отримані результати 3 даними літературних джерел, ми пересвідчились, що запровадження дистанційного навчання негативним чином позначилося на стилі життя студенток. Багато з них дедалі більше часу проводить у статичному положенні сидячи, що не сприяє збереженню їхього здоров'я.

Постала необхідність у термінових заходах, спрямованих на підвищення рухової активності студенток гуманітарних ЗВ0, залучення їх до активно- 
го способу життя. На нашу думку, існує потреба в підготовці відеозаписів комплексів фрізичних вправ із використанням засобів черлідингу для підвищення мотивації студенток до фрізкультурно-оздоровчих занять.

Перспективи подальших досліджень передбачають розробку пропозицій, спрямованих на підвищення рівня срізичної активності студенток гуманітарних 3ВО в умовах дистанційного навчання.

Конфлікт інтересів. Автор заявляє, що відсутній будь-який конфрлікт інтересів.

\section{ЛIТЕРАТУРА}

1. Бишевець НГ. Здоров'язбережувальна технологія навчання майбутніх учителів фізично культури в умовах інформатизації освіти Гавто реферат]. Луцьк: Східноєвропейський нац. ун-т ім. Лесі Українки. 2018. 23 с.

2. Бишевець Н, Гончарова Н. Фізична активність студенток закладів вищої освіти. В: IV Міжнар. науково-практ. ІІнтернет-консреренція «Фізична активність і якість життя людини». 2020. С. 9.

3. Кашуба В0, Бишевець НГ, Альошина AІ, Бичук ОІ. Здоров'язбережувальна технологія навчання майбутніх учителів фізичної культури в умовах інформатизації освіти. Луцьк : ВежаДрук. 2019. 222

4. Ковтун А. Рухова активність студенток вищих навчальних закладів. Молода спортивна наука України. 2015;2:105-108.

5. Миронюк I, Дуб М. Характерні особливості рухової активності та дієздатност студенток 3 ожирінням Вісник Прикарпат. університету. Серія: Фізична культура. 2019;34 DOI: https://doi.org/10.15330/fcult.34.53-60.

6. Плєшакова ОВ. Черлідинг - як складова здорового способу життя студентської молоді. Науковий часопис. 2018;1(95):54-57.

7. Плєшакова ОВ. Організаційно-методичні основи педагогічного управління фізичним потенціалом студентів нефрізкультурних ви щих навчальних закладів. Науковий часопис 2018;1(95);30-33.

8. Попович ДВ, Сопель ОМ, Бондарчук ВІ, Дяченко ММ. Аналіз фізичної активності студенток першого року навчання в Тернопільському державному медичному університеті імен І. Я. Горбачевського. Здобутки клінічної експериментальної медицини. 2018;4:123-127. DOI 10.11603/1811-2471.2018.v0.i4.9743.

9. Редькіна М. Особливості індивідуально рухової активності студентів педагогічних спеціальностей Гірська школа українських Карпат. 2019;21:78-81. doi: 10.15330/msuc.2019.21.78-81.

10. Селіванов $€ B$. Значення фрізичної активності студентської молоді у процесі формування особистості. Актуальні проблеми фізичного виховання різних верств населення. 2018;220-226.

11. Цьось А, Шевчук А, Касарда О. Рухова активність у мотиваційно-ціннісних орієнтаціях студентів. Фізичне виховання, спорт і культура здоров'я у сучасному суспільстві: зб. наук. пр. Східноєвроп. нац. ун-ту ім. Лесі Українки. Луцьк: Східноєвроп. нац. ун-т ім. Лесі Українки, 2014;4(28):83-87.
12. Byshevets N. Express estimation of the user's working posture in learning process. Journal of Education, Health and Sport. 2017; 7(8) 1628-41.

13. Byshevets N, Denysova L, Shynkaruk 0 Serhiyenko K, Usychenko V, Stepanenko 0, Syvash I. Using the methods of mathematical statistics in sports and educational research. Journal of Physical Education and Sport. 2019;19(148):1030 1034. DOl:10.7752/jpes.2019.s3148

14. Byshevets N, Shynkaruk O, Stepanenko 0, Gerasymenko S, Tkachenko S, Synihovets I Filipov V, Serhiyenko K, lakovenko O. Development skills implementation of analysis of variance at sport-pedagogical and biomedical researches. Journal of Physical Education and Sport (JPES) 2019;19(311):2086-2090. DOI:10.7752/jpes.2019. s6311.

15. Denysova L, Byshevets Na, Shynkaruk 0, Imas Ye, Suschenko L, Bazylchuk 0, Oleshko T, Syvash I, Tretiak 0. Theoretical aspects of design and development of information and educational environment in the system of training of masters in physical culture and sport. Journal of Physical Education and Sport. 20(145):324-330. DOI:10.7752/jpes.2020.s1045.

16. Kashuba V, Stepanenko O, Byshevets N Kharchuk 0, Savliuk S, Bukhovets B, Grygus Napierała M, Skaliy T, Hagner-Derengowska M, Zukow W. The Formation of Human Movement and Sports Skills in Processing Sports pedagogical and Biomedical Data in Masters of Sports. International Journal of Human Movement and Sports Sciences. 2020;8(5):249-257. DOI: 10.13189/saj.2020.080513

\section{LITERATURE}

1. Byshevets $\mathrm{NH}$. Health protecting techno logy of teaching future physical culture teachers in conditions of informative education [author's abstract]. Lutsk: Skhidnoievropeyskyi natsionalnyi universytet imeni Lesi Ukrainky. 2018. 23 p.

2. Byshevets N, Honcharova N. Physical activity of female university students. In: IV Mizhnar. naukovo-praktychna Internet-konferentsiia «Phys ical activity and human life quality». 2020. P. 9.

3. Kashuba V0, Byshevets NH, Alioshyna Al, Bychuk OI. Health protecting technology of teaching future physical culture teachers in conditions of informative education. Lutsk: Vezha-Druk. 2019 $222 \mathrm{p}$.

4. Kovtun A. Motor activity of university female students. Moloda sportyvna nauka Ukrainy. 2015;2:105-108.

5. Myroniuk I, Dub M. Peculiar features of obese female student motor activity and efficiency. Visnyk Prykarpat. universytetu. Series: Physica culture. 2019;34: DOI: https://doi.org/10.15330/ fcult $34.53-60$.

6. Pleshakova OV. Cheerleading as a constituent of student youth healthy life style. Naukovyi chasopys. 2018;1(95):54-57.

ІНФОРМАЦІЯ ПРО АВТОРА

Плєшакова Олена Володимирівна https:orcid.org/0000-0002-7163-6239, helena.oleena@gmail.com Київський національний університет культури та мистецтв 01133, Київ, вул. Є. Коновальця, 36

\section{INFORMATION ABOUT THE AUTHOR}

Plyeshakova Olena https: orcid.org/0000-0002-7163-6239, helena.oleena@gmail.com Kyiv National University of Culture and Arts 01133, Kyiv, street E. Konovalets, 36
7. Pleshakova OV. Organizational and meDiachenko MM. Analysis of physical activity of first-year students at Ternopil State Medical Uni-

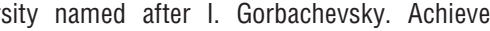
ticine v0.i4.9743.

9. Redkina M. Peculiarities of individual mo or activity of pedagogical specialty students. school of the Ukrainian Carpathians. 81

10. Selivanov IV. Significance of student youth motor activity in the process of personality formation. Aktualni problem fizvykhovannia riznykh ver(2018;220-226. dorovia u suchasnomu suspilstvi. Zb. nauk. prats.

.

the user's working posture in learning process Journal of Education, Health and Sport. 2017; 7(8):

13. Byshevets N, Denysova L, Shynkaruk 0 Serhiyenko K, Usychenko V, Stepanenko 0, Syvash . Using the methods of mathematical statistics sports and educational research. Journal of 1034. DOI:10.7752/jpes.2019.s3148,

14. Byshevets N, Shynkaruk 0, Stepanenko 14. pov V, Serhiyenko K, lakovenko 0. Development skills implementation of analysis of variance at sportpiomedical researches. Journal of DOl:10.7752/jpes.2019.s6311. design and development of information and in sport. Journal DOI:10.7752/jpes.2020.s1045

16. Kashuba V, Stepanenko 0, Byshevets N Kharchuk 0, Savliuk S, Bukhovets B, Grygus I

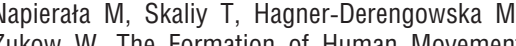
and Sports Skills in Processing SportsS International Journal of Human Movement and Sports Sciences. 2020;8(5):249-257. DOI: $10.13189 /$ saj.2020.080513

\section{Надійшла 27.11.2020}

8. Popovych DV, Sopel OM, Bondarchuk VI, 